\title{
FORECASTING RADIATION EFFECTS ON WILDLIFE IN JAPAN AFTER THE FUKUSHIMA NUCLEAR ACCIDENT, BASED ON LIMITED INFORMATION OF POST- ACCIDENT EARLY STAGE IN 2011
}

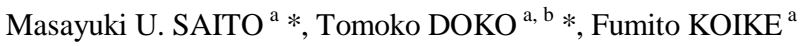 \\ ${ }^{a}$ Research Institute of Environment and Information Sciences, Yokohama National University, 79-7 Tokiwadai, Hodogaya-ku, \\ Yokohama city, Kanagawa Prefecture, 240-8501 Japan \\ ${ }^{\mathrm{b}}$ Research Fellow of the Japan Society for the Promotion of Science, Sumitomo-Ichibancho FS Bldg., 8 Ichibancho, Chiyoda-ku, \\ Tokyo 102-8472 Japan - dokochan@sfc.keio.ac.jp \\ * These authors contributed equally to this work. T. Doko is a corresponding author.
}

Technical Commission II

KEY WORDS: Ecology, GIS, Hazards, Impact Analysis, Pollution, Prediction, Temporal, Visualization

\begin{abstract}
:
Due to the 11 March 2011 Tohoku earthquake, massive radioactive materials were released from the Fukushima Daiichi Nuclear Power Plant (Fukushima NPP). It is crucial to predict the regional distribution and magnitude of the effects on wildlife by radioactive materials. However, during the post-accident early stage in 2011, limited information on large-scale pollution and prediction maps was open to public. Hence, this paper aimed to provide (1) the pollution map covering areas within $300 \mathrm{~km}$ from the Fukushima NPP where the radiation intensity exceeded $0.5 \mu \mathrm{Sv} / \mathrm{h}$, (2) pollution maps which predicted air dose for the next 30 years after the accident, and (3) maps of areas where wildlife might be affected by radioactive isotopes by the Fukushima nuclear accident. First, the relative contributions of ${ }^{131} \mathrm{I},{ }^{134} \mathrm{Cs}$, and ${ }^{137} \mathrm{Cs}$ were estimated from time series observation data. Second, a 30-year prediction of the pollution was calculated based on the isotope half-lives. Third, the chronic radiation effects on vertebrates were estimated using the threshold dose rate proposed by Sazykina et al. (2009). We examined the chronic radiation effects on morbidity, reproduction, and longevity. The results indicated that radioactive materials could have affected vertebrate morbidity within a $350 \mathrm{~km}^{2}$ area in early April 2011; the threshold level was the median result of Sazykina et al. (2009) with bootstrapping. Based on the prediction, a $15.5 \mathrm{~km}^{2}$ region will remain affected after 30 years. These areas should be monitored to confirm the effects of radioactivity on wildlife.
\end{abstract}

\section{INTRODUCTION}

Following the 9.0 magnitude Tohoku earthquake and tsunami on 11 March 2011 and the accident at the Tokyo Electric Power Company (TEPCO) Fukushima Daiichi (No. 1) Nuclear Power Plant (NPP), radioactive material was released into the environment (Science Council of Japan, 2011). Between 11 March and 5 April, an estimated 150,000 TBq of iodine-131 $\left({ }^{131} \mathrm{I}\right)$ and $12,000 \mathrm{TBq}$ of cesium-137 $\left({ }^{137} \mathrm{Cs}\right)$ were released into the atmosphere, based on back-calculations by the System for Predicting Environmental Emergency Dose Information (SPEEDI; Science Council of Japan, 2011). In addition, an estimated $2800 \mathrm{TBq}$ of ${ }^{131} \mathrm{I}, 13,1940 \mathrm{TBq}$ of cesium-134 $\left({ }^{134} \mathrm{Cs}\right)$, and $940 \mathrm{TBq}$ of ${ }^{137} \mathrm{Cs}$ were released into the ocean (Science Council of Japan, 2011). SPEEDI was designed to predict radioactive material concentrations in the environment rapidly after a large release based on emission source data, while considering topography and wind and rain measurements (Science Council of Japan, 2011). According to the Nuclear and Industrial Safety Agency (NISA), the total amount of radioactive material released into the atmosphere was about $10 \%$ of that released from the Chernobyl accident in 1986 (Science Council of Japan, 2011). As of 17 August 2011, people within a 1,595 $\mathrm{km}^{2}$ area were urged to evacuate or to be ready for emergency evacuation.

Based on calculations of the radiological dose received by forest and marine biota within 30 days of the Fukushima nuclear accident, radioactive material from the accident affected forest and coastal ecosystems during that period (Garnier-Laplace et al., 2011). Since mammals are the most sensitive group to radiation exposure, while invertebrates and simpler organisms are relatively insensitive (Beresford and Copplestone, 2011), radioactive material from the accident could continue to affect vertebrates. It is crucial to predict the regional distribution and magnitude of the effects on vertebrates by radioactive materials.

However, in the post-accident early stage, whole Japan including the government of Japan, TEPCO, and Japanese citizens fell into a state of chaos. Hence, crucial information regarding radioactive materials, e.g. the spatial distribution and magnitude of pollution level, was kept quiet. For instance, although SPEEDI was implemented and operated for the purpose of predicting radioactive material concentrations in a spatially-explicit manner, the results of calculation by SPEEDI were not used for decision of evacuation. Also, it took time to open information of calculation by SPEEDI to public. In the post-accident early stage in 2011, only a single pollution map of a limited area was available opened by MEXT (2011), while no predicted pollution map was available. We are not radiation experts. Nevertheless, in such a chaos, we believed that we should take an initiative for opening information regarding spatial distribution and magnitude of pollution level of radioactive materials because Research Institute of Environment and Information Sciences of Yokohama National University is a well-known institute for risk assessment for the ecosystem. We also believed that this kind of research 
activities would contribute to the society and stimulate disclosure of information by other organizations. Hence, Fumito Koike headed up research on "Forecasting radiation effects on wildlife in Japan after the Fukushima nuclear accident." The research team members were composed on Masayuki SAITO, Tomoko DOKO, and Fumito KOIKE from Yokohama National University. Since there was no research budget for this project, we started a volunteer-based research project in order to predict radiation effects on wildlife due to Fukushima nuclear accident. Using time period and data from March to June 2011, we completed all analysis and opened results through http://vege1.kan.ynu.ac.jp/lab/nc/ (individual website of Fumito Koike, Yokohama National University) on 23 July 2011. The current work presented in this paper is a summary of the research project and hence it relied on limited information of post-accident early stage from March to June 2011.

This study examined the spatial distribution of radiation effects on vertebrates for 30 years after the Fukushima nuclear accident. First, we estimated the magnitude of the current regional distribution of influences and calculated a 30-year prediction, for which large-scale pollution and future prediction maps were necessary. We prepared a large pollution map covering areas where the radiation intensity exceeded $0.5 \mu \mathrm{Sv} / \mathrm{h}$. The relative contributions of ${ }^{131} \mathrm{I},{ }^{134} \mathrm{Cs}$, and ${ }^{137} \mathrm{Cs}$ were estimated from time series data. The map of pollution changes over 30 years was calculated based on the half-lives of these isotopes.

Our work priority was efficiency at that time; we attempted to open the calculate results as soon as possible to meet public demands. We believe that when there is not sufficient information, we first need to rely on limited information of postaccident early stage and need to conduct prediction with simple assumption. In a later period, when more information will be available, prediction could be improved. Hence, to understand assumption we used for the further analysis in this study is crucial. This paper has following assumptions.

Changes in high pollution areas, where chronic radiation significantly affected vertebrates, were predicted using the threshold dose rate proposed by Sazykina et al. (2009), based on accidents in Russia and experiments. We considered the effects of chronic radiation on morbidity, reproduction, and longevity. In this study, acute effects were not considered, as areas $>1 \mathrm{mSv} / \mathrm{h}$ were likely limited to within $1 \mathrm{~km}$ of the NPP. Furthermore, genetic effects from lower doses were not evaluated, as they have not been studied well in wildlife.

In this paper, we did not distinguish between external doses and internal ones due to following reasons. The spatial distribution of radiation intensity around and inside an organism, and ultimately within a cell, is vital in determining the dose. In general, humans live in low radiation environments and have low body doses. High-dose foods are sometimes consumed, and hence the dose coefficient is useful in estimating the cumulative dose for individuals. On contrary, some wild animals inhabit environments under high levels of radiation dose and always eat high-dose foods. Because isotope equilibriums are thought to form within animals as well as their ecosystem, one informative measure is the radioactive isotope concentration in organisms and the transfer factor, organism radiation/soil radiation, is a useful property. However, these values have not been determined well in Japan. Dose coefficients, the cumulative human dose/isotope concentration in food, are used to estimate human internal doses, but measuring the dose coefficients of various ecosystem components, including water, leaves, fruit, and prey, for multiple wildlife with varying food habits, including carnivory, insectivory, herbivory, frugivory, detritivory, and omnivory, is infeasible. Instead, we assumed that radiation intensity distribution in animals and the surrounding atmosphere are spatially even, in order to respond promptly to emergent information needs regarding ecological consequences of the Fukushima nuclear accident. Since the accident, air radiation measurements have been usually conducted close to soil surface, we considered the air radiation measurements are more or less equivalent to the radiation intensity to the ecosystem.

This paper aimed to provide (1) the pollution map covering areas within $300 \mathrm{~km}$ from the Fukushima NPP where the radiation intensity exceeded $0.5 \mu \mathrm{Sv} / \mathrm{h}$, (2) pollution maps which predicted air dose for the next 30 years after the accident, and (3) maps of areas where wildlife might be affected by radioactive isotopes by the Fukushima nuclear accident, using limited information of post-accident early stage.

\section{MATERIALS AND METHODS}

\subsection{Estimation of the contribution ratio of radionuclides}

After the Fukushima nuclear accident, many organizations began monitoring air radiation dose rates and opened data to public inspection through websites. However, at many of these "temporal" monitoring locations, air radiation dose was often measured merely once or a few times. Thus, the contribution ratio of radionuclides at the initial dose rate needed to be estimated first. Hence, we obtained dose measurement data from 49 localities at "fixed" monitoring locations in Fukushima, Ibaraki, Tochigi, and Kanagawa Prefectures from 15-18 March until 30 June 2011. In these fixed monitoring sites, air radiation doses are continuously and regularly collected, and even before this nuclear accident these facilities have been operated. We calculated mean value of radiation dose and converted its unit to $\mu \mathrm{Sv} / \mathrm{h}$. The main radionuclides discharged into the atmosphere were ${ }^{131} \mathrm{I},{ }^{134} \mathrm{Cs}$, and ${ }^{137} \mathrm{Cs}$ (Science Council of Japan, 2011) which have half-lives of 8.02, 753.8, and 11,012 days, respectively. Thus, the initial dose rate contribution ratio of nucleotides on 15 March 2011 should be calculated using the difference in their half-life by the equation (1):

$$
\begin{gathered}
y={ }^{131} \mathrm{I} \times(1 / 2)^{t / 8.02}+{ }^{134} \mathrm{Cs} \times(1 / 2)^{t / 753.8}+{ }^{137} \mathrm{Cs} \times \\
(1 / 2)^{t / 1012}+0.05
\end{gathered}
$$

where $y$ is the dose rate $(\mu \mathrm{Sv} / \mathrm{h})$ which was continuously measured from immediately after the accident (around 15 March 2011) to 30 June 2011; and $t$ is the number of days elapsed from the start (15 March 2011).

As for the intercept, we adapted $0.05 \mu \mathrm{Sv} / \mathrm{h}$, which is the average value of Japanese background terrestrial radiation dose rate, according to UNSCEAR (2000). The "nls" function in R 2.11.1 software (R Development Core Team, 2010) was used to apply a nonlinear model for determining the nonlinear least-squares estimates of the parameters. 
However, equation 1 has some problems. One issue is that we could not estimate the ${ }^{134} \mathrm{Cs}$ and ${ }^{137} \mathrm{Cs}$ doses separately because the half-life of $\mathrm{Cs}$ was longer than the time span of the measurement data. Therefore, ${ }^{134} \mathrm{Cs}$ and ${ }^{137} \mathrm{Cs}$ were assembled as "Cs" using 11,012 days for its half-life by equation (2). Another problem is that the air dose rate around 15 March 2011 was varied in many regions due to radioactive noble gases and rainfall. Therefore, we used the stable value measured on and after 23 March 2011 by equation (2).

$$
y={ }^{131} \mathrm{I} \times(1 / 2)^{t / 8.02}+\operatorname{Cs} \times(1 / 2)^{t / 11012}+0.05
$$

where $y$ is the measured dose rate $(\mu \mathrm{Sv} / \mathrm{h})$ on and after 23 March 2011 to 30 June 2011; and $t$ is the number of days elapsed from the start (15 March 2011); 0.05 ( $\mu \mathrm{Sv} / \mathrm{h}$ ) for the intercept.

From equation (2), the contribution ratio of ${ }^{131} \mathrm{I}$ was estimated to be $0.8 \pm 0.1$ (mean $\pm \mathrm{SD}$ ), and that of Cs was $0.2 \pm 0.1$, based on a nonlinear model. Since the ratio of ${ }^{134} \mathrm{Cs}:{ }^{137} \mathrm{Cs}$ was almost $1: 1$ according to the soil nuclide ratio measurement in Fukushima City by Fukushima University (Radiation measurement team of Fukushima University, 2011), we assumed that the contribution ratios of ${ }^{134} \mathrm{Cs}$ and ${ }^{137} \mathrm{Cs}$ were both 0.1 , and used these calculated contribution ratios to predict the future air dose rate. Hence, we determined the contribution ratios of ${ }^{131} \mathrm{I}:{ }^{134} \mathrm{Cs}:{ }^{137} \mathrm{Cs}=8: 1: 1$.

\subsection{The air radiation dose rate prediction}

In order to predict future air radiation dose rate, we obtained a dose measurement data for four months after the accident from websites of the TEPCO, the Ministry of Education, Culture, Sports, Science, and Technology (MEXT), local governments, and Fukushima University. In total, 11,824 localities, which have geographical coordinates (latitude and longitude) and air radiation dose rates, were collected (Fig. 1). Units of these dose rates were converted to $\mu \mathrm{Sv} / \mathrm{h}$. Cesium, with a much greater halflife than ${ }^{131} \mathrm{I}$, is an important source of radiation. Since positive Cs ions are attracted to negatively charged clay particles in soil, Cs was assumed not to have secondary movement over a large spatial scale. Based on the measured air radiation dose rate and estimated contribution rate and half-life of the nuclide, the air radiation dose rate from 1 April 2011 to 1 April 2041 was predicted. First, we converted the dose rate at each time logarithmically. Next, we conducted spatial interpolations using the inverse distance weighted method (IDW: Watson and Philip, 1985; Burrough and McDonnell, 1998) using ArcMap $^{\circledR} 9.3$ (ESRI). The IDW interpolation technique determines cell values using a linearly weighted combination of sample points. The target area was set as the area within a $300-\mathrm{km}$ radius of the Fukushima NPP. Finally, the air dose rate prediction map was made by converting the anti-logarithm of the space interpolation value. The area $\left(\mathrm{km}^{2}\right)$ above each radiation intensity level $(\geq 0.5$, $1,5,10,50,100 \mu \mathrm{Sv} / \mathrm{h})$ and the maximum distance $(\mathrm{km})$ from the Fukushima NPP were computed by ArcMap ${ }^{\circledR}$ 9.3.

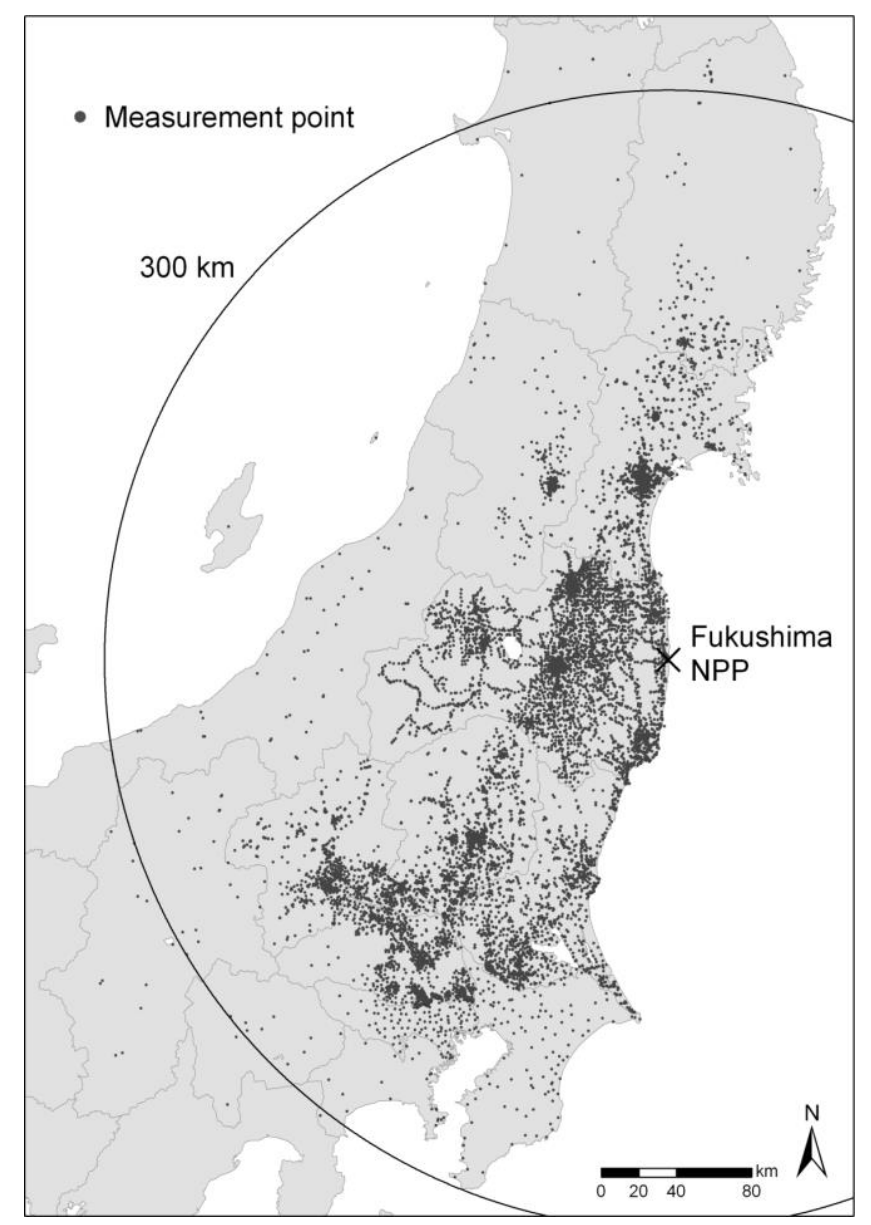

Figure 1. Locations of the Fukushima Daiichi Nuclear Power Plant and dose measurement points $(\mathrm{n}=11,824)$. The measurement points were available on the TEPCO, MEXT, local government, and Fukushima University websites. 


\subsection{Radiation effect map for vertebrates}

Radiation can have acute or chronic effects. Since acute effects would most likely be limited to near the Fukushima NPP, we did not examine them. Rather, we forecasted chronic effects on vertebrates exposed to radiation over several generations. Details of the effects of radioactive material on ecosystems are not yet available. Moreover, how cumulative dose of radioactive material have an effect on various species or organism organs is unknown. Therefore, in this study, we assumed that all environments, including soil and organisms, experienced the same dose rate. Hence, the air radiation dose rate was assumed to be almost similar to the one for the wildlife exposure, although it is considered rough approximation.

First, based on above-mentioned air radiation dose rate prediction, we computed the mean value of the predicted air dose rate over 20 days, which corresponds to the pregnancy period of the large Japanese field mouse, Apodemus speciosus (Ohdachi et $a l ., 2009)$. There was considerable variation in the data collected in the beginning 20 days after the accident (265 points in total, 15 March - 3 April 2011), due to radioactive noble gases and rainfall. Therefore, these observed values were used to calculate the mean value, for this period, as an exception. Additionally, values within $20 \mathrm{~km}$ of the Fukushima NPP and other missing values were interpolated using predicted values due to lack of accurate observed values. In order to simplify the prediction, we used the 20 days pregnancy period in this study. However, to have more robust prediction for future work, it is recommended to consider chronic long-term exposure all over life span and across multiple generations.

Secondly, following Sazykina et al. (2009), animal radiation

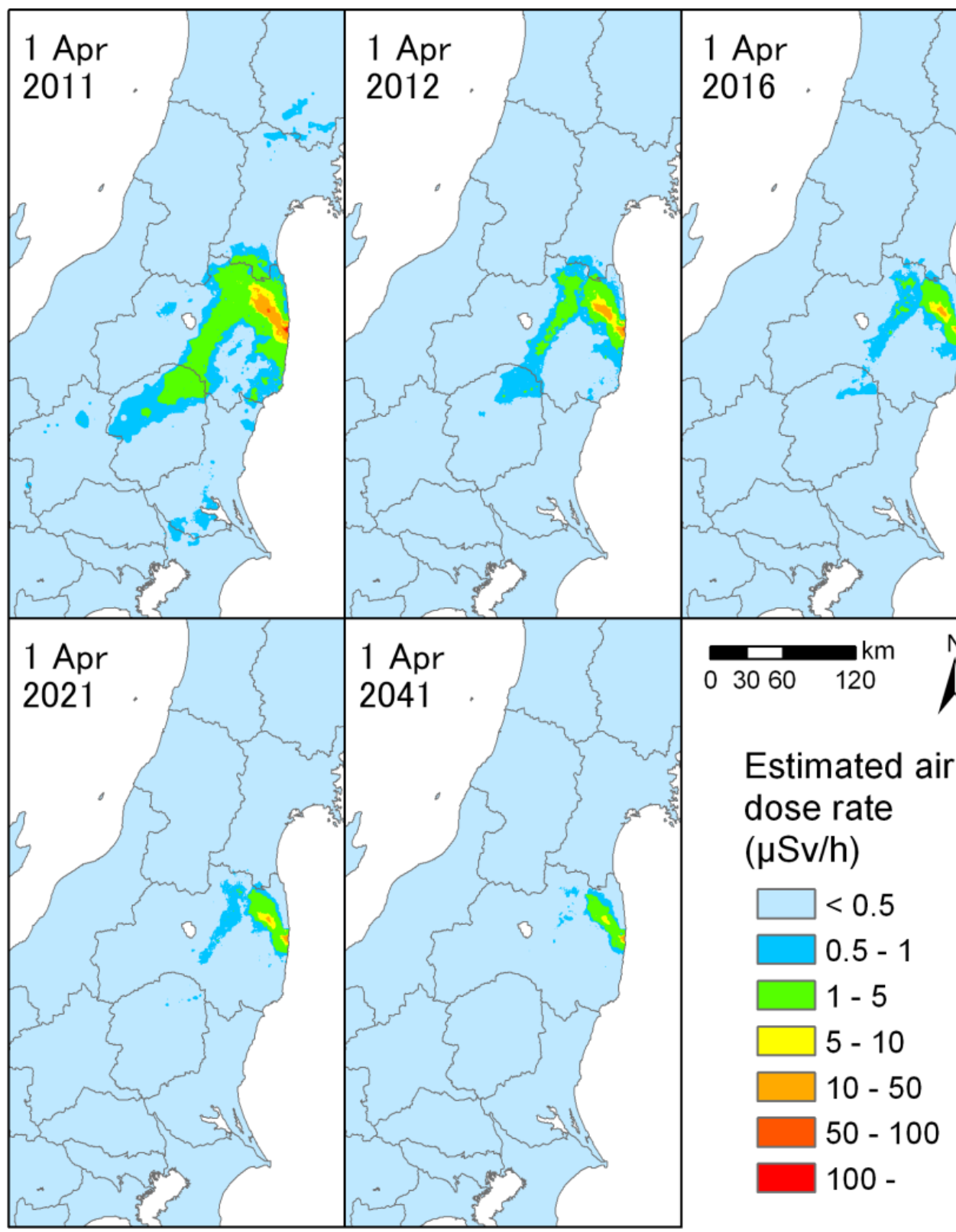

Figure 2. The 30-year air dose rate forecast $(\mu \mathrm{Sv} / \mathrm{h})$ for $2011-2041$. The map was made by converting the dose rates from the 11,824 measurement points using the inverse distance weighted method. 

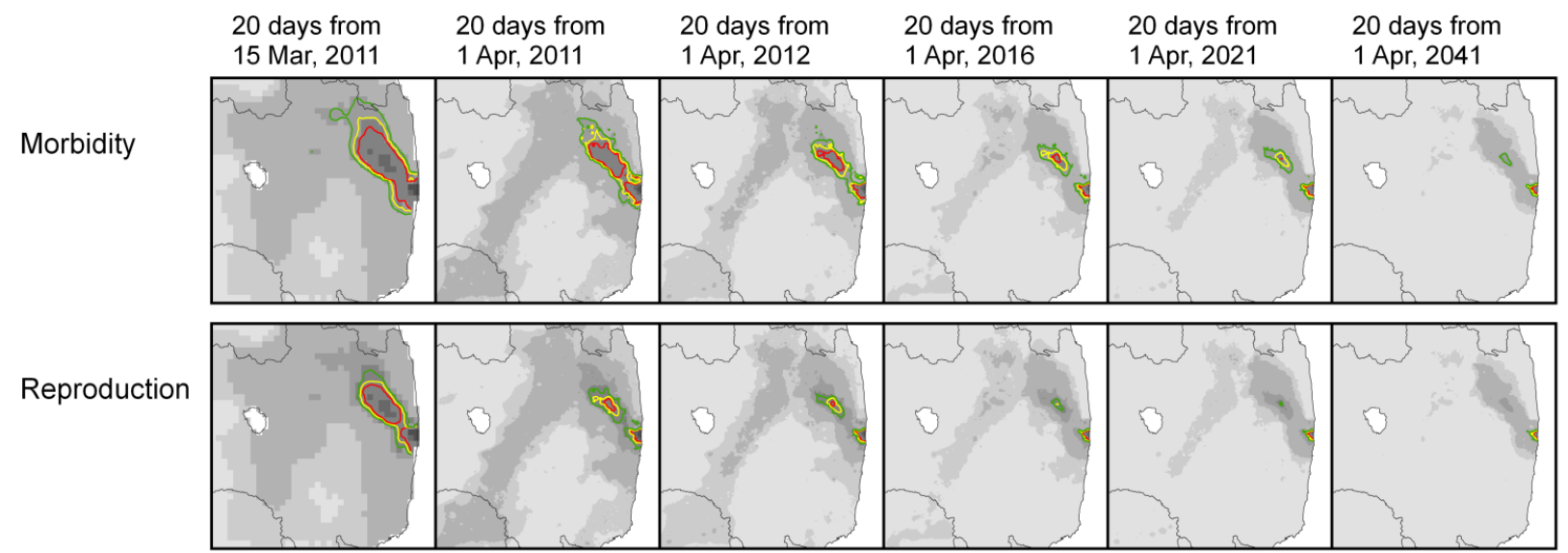

Longevity
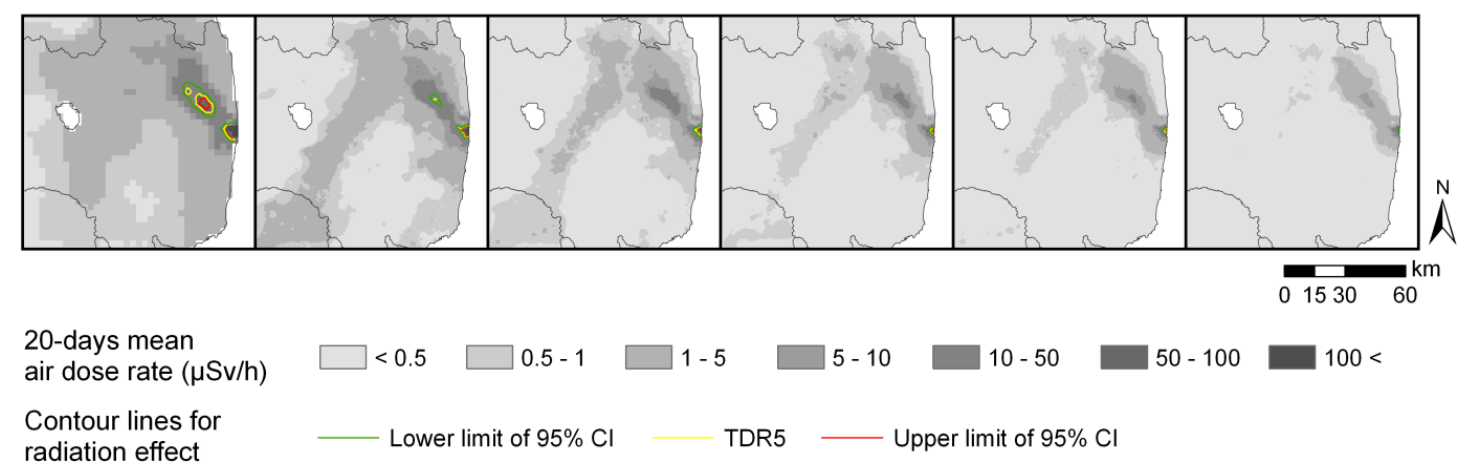

Figure 3. Radiation effect maps for morbidity, reproduction, and longevity in vertebrates subject to chronic exposure around the Fukushima NPP. We drew the contour lines using the 5\% threshold dose rate estimation (TDR5) and 95\% CI of the thresholds suggested by Sazykina et al. (2009) on a map of the 20-day mean air dose rate.

effects were categorized into three endpoints: morbidity, reproduction, and longevity. We adopted a 5\% threshold dose rate (TDR5) for radiation effects in vertebrates under chronic low-LET exposures, which was calculated based on the bootstrap method by Sazykina et al. (2009). The proper unit to express dose rate for non-human species is the Gy per unit time and the $\mathrm{Sv}$ is a risk metric dedicated to human radioprotection. However, because dose rate was often measured in Sv, the units of the TDR5 values were converted into $\mu \mathrm{Sv} / \mathrm{h}$. TDR 5 were expressed as $5.8-13.3,12.5-23.8$, and $32.9-54.2 \mu \mathrm{Sv} / \mathrm{h}$ for morbidity, reproduction, and longevity, respectively.

Lastly, we made three forecast maps for radiation effects by drawing contour lines using the thresholds for the three endpoints on the 20-day mean dose rate map. The predicted area $\left(\mathrm{km}^{2}\right)$ of radiation effects on vertebrates and the maximum distance $(\mathrm{km})$ from Fukushima NPP were computed by $\operatorname{ArcMap}^{\circledR}$ 9.3.

\section{RESULTS AND DISCUSSION}

The predicted air radiation dose rate on 1 April 2011 was high near and northwest of the Fukushima NPP, with severe locallydistributed high dose rate near Namie and Iitate (Fig. 2). The area where radiation exceeded $5 \mu \mathrm{Sv} / \mathrm{h}$ covered $756 \mathrm{~km}^{2}$, and extended as far as $58.3 \mathrm{~km}$ from the NPP (Table 1). The area exceeding $1 \mu \mathrm{Sv} / \mathrm{h}$ covered 5,332 $\mathrm{km}^{2}$ (Table 1). Lower dose level at locally-distributed area, where radiation exceeded 0.5 $\mu \mathrm{Sv} / \mathrm{h}$, were widely distributed over $5,332 \mathrm{~km}^{2}$, southwest to the border of Nagano and Gunma prefectures $256 \mathrm{~km}$ from the NPP, southwest to northern Chiba prefecture $209 \mathrm{~km}$ away, and north to southern Iwate prefecture, $197 \mathrm{~km}$ from the NPP. The predicted air radiation dose rate in severe locally-distributed area near Namie and Iitate after 30 years was $>1 \mu \mathrm{Sv} / \mathrm{h}$ over $578 \mathrm{~km}^{2}$ (Table 1), although the dose rate will diminish over time because the half-life of ${ }^{137} \mathrm{Cs}$ is about 30 years.

After the Fukushima nuclear accident, wildlife northwest of the Fukushima NPP likely experienced negative effects on morbidity, reproduction, and longevity, from radioactive material (Fig. 3). The greatest extent of the impact was on morbidity, which affected a $350 \mathrm{~km}^{2}$ area, up to $42.3 \mathrm{~km}$ from the NPP, followed by the impacts on reproduction, which affected a $156 \mathrm{~km}^{2}$ area, up to $33.4 \mathrm{~km}$ from the NPP, and longevity $\left(18 \mathrm{~km}^{2}\right.$, up to 22.5 $\mathrm{km}$ from the NPP), on 1 April 2011 (Table 2).

Near the Fukushima NPP, all radiation effects were expected to remain for 30 years. Moreover, in the northwest region, effects on morbidity were expected to last for 30 years in a $15.5 \mathrm{~km}^{2}$ area, extending up to $5.28 \mathrm{~km}$ from the NPP, and effects on and reproduction were expected to last in a $6.25 \mathrm{~km}^{2}$ area, extending up to $3.4 \mathrm{~km}$ from the NPP, although the extent of the effects was predicted to decrease over time (Table 2). 


\begin{tabular}{|l|c|c|c|c|c|}
\hline Air dose rate $(\mu \mathrm{Sv} / \mathrm{h})$ & Apr 1,2011 & Apr 1,2012 & Apr 1,2016 & Apr 1, 2021 & Apr 1, 2041 \\
\hline$\geq 0.5$ & $11052(256)$ & $5010(191)$ & $3093(120)$ & $2072(117)$ & $1030(80.9)$ \\
$\geq 1$ & $5332(191)$ & $1924(117)$ & $1047(81)$ & $818(61.8)$ & $578(48)$ \\
$\geq 5$ & $756(58.3)$ & $360(42.3)$ & $217(34.4)$ & $154(33.4)$ & $56.3(29.9)$ \\
$\geq 10$ & $422(44.5)$ & $155(33.4)$ & $64(30.2)$ & $34.3(24.8)$ & $13.8(4.21)$ \\
$\geq 50$ & $27.3(24.5)$ & $7.5(3.61)$ & $3.5(2.3)$ & $1.75(1.67)$ & $0.25(0.76)$ \\
$\geq 100$ & $9.75(3.78)$ & $1.75(1.7)$ & $0.25(0.79)$ & $0.25(0.68)$ & $0(-)$ \\
\hline
\end{tabular}

Table 1. The area $\left(\mathrm{km}^{2}\right)$ above each radiation intensity level. The maximum distance $(\mathrm{km})$ from the Fukushima Daiichi NPP is in the prances.

\begin{tabular}{|l|l|c|c|c|c|c|c|}
\hline \multicolumn{2}{|c|}{ Radiation effect } & $\begin{array}{c}\text { 20 days from } \\
\text { Mar 15, 2011 }\end{array}$ & $\begin{array}{c}\text { 20 days from } \\
\text { Apr 1, 2011 }\end{array}$ & $\begin{array}{c}20 \text { days from } \\
\text { Apr 1, 2012 }\end{array}$ & $\begin{array}{c}20 \text { days from } \\
\text { Apr 1, 2016 }\end{array}$ & $\begin{array}{c}20 \text { days from } \\
\text { Apr 1, 2021 }\end{array}$ & $\begin{array}{c}20 \text { days from } \\
\text { Apr 1, 2041 }\end{array}$ \\
\hline \multirow{3}{*}{ Morbidity } & TDR5 & $765(46.4)$ & $350(42.3)$ & $185(34)$ & $84.3(30.6)$ & $49(25.2)$ & $15.5(5.28)$ \\
& Lower 95\% CI & $522(39.8)$ & $218(34.4)$ & $92(30.7)$ & $32.5(24.7)$ & $18(22.5)$ & $9.5(3.77)$ \\
& Upper 95\% CI & $1098(59.5)$ & $554(48)$ & $305(40.1)$ & $178(33.9)$ & $119(32.2)$ & $40.3(24.9)$ \\
\hline \multirow{3}{*}{ Reproduction } & LDR5 & $414(37.1)$ & $156(33.4)$ & $53(25.5)$ & $18(22.5)$ & $12.8(3.66)$ & $6.25(3.4)$ \\
& Lower 95\% CI & $315(35.4)$ & $82.6(30.6)$ & $22(23.4)$ & $12(3.92)$ & $8(2.78)$ & $3.5(2.25)$ \\
\hline \multirow{2}{*}{$\begin{array}{l}\text { Life } \\
\text { shortening }\end{array}$} & Upper 95\% CI & $549(41)$ & $237(34.6)$ & $106(32)$ & $39.3(24.9)$ & $20(4.17)$ & $10(3.82)$ \\
\hline & Lower 95\% CI & $63(22.7)$ & $14.8(5.19)$ & $7(3.48)$ & $2.75(2.09)$ & $1.5(1.46)$ & $0.25(0.73)$ \\
& Upper 95\% CI & $198(33.7)$ & $41.5(24.9)$ & $14.3(4.22)$ & $7.5(3.57)$ & $5.25(2.78)$ & $1.5(1.46)$ \\
\hline
\end{tabular}

Table 2. The predicted area $\left(\mathrm{km}^{2}\right)$ of radiation effects on vertebrates. The maximum distance $(\mathrm{km})$ from Fukushima Daiichi NPP is in prances.

We evaluated radiation effects at an individual level, but did not examine the population effects. Individual longevity and reproduction, i.e., the number of offspring from one female, are important parameters in population studies. Morbidity indirectly affects populations by affecting longevity, reproduction, and immigration activity in meta-population processes. Populationlevel performance would likely decrease in areas with diminished reproduction or longevity. The estimated area of such effects was $156 \mathrm{~km}^{2}$ in April 2011, $12.8 \mathrm{~km}^{2}$ after 10 years, and $6.25 \mathrm{~km}^{2}$ after 30 years (Table 2).

Animal abundance in natural ecosystems is not only determined by longevity and reproduction. Other factors determine local abundance, including resource competition, predation, and immigration. Natural immigration from surrounding lowpollution areas may obscure radiation damage. Since a narrow area was expected to experience population damage from the Fukushima accident, with a maximum width of $6.5 \mathrm{~km}$ in April 2011, $2.8 \mathrm{~km}$ after 10 years, and $1.9 \mathrm{~km}$ after 30 years (Fig. 3), birds and large mammals can easily immigrate to the area (Olival and Higuchi, 2006; Ohdachi et al., 2009).

According to the government, humans were evacuated or were ready to evacuate from a wider area of about $1,600 \mathrm{~km}^{2}$ within $20 \mathrm{~km}$ of the Fukushima NPP and its surrounding high-radiationdose zone to avoid health risks, such as cancer, induced by lowlevel radiation (NISA, 2011; Science Council of Japan, 2011). Moreover, the government recommended evacuating humans in areas where radiation was estimated to exceed $20 \mathrm{mSv} / \mathrm{year}$, approximately $2.3 \mu \mathrm{Sv} / \mathrm{h}$ (NISA, 2011). However, it is not likely that wildlife longevity and reproduction will be affected at these human evacuation threshold levels. After human evacuation, the traditional rural Japanese landscape of scattered forests and abandoned croplands became suitable habitat for large animals, including wild boar, Sus scrofa, and sika deer, Cervus nippon (Miyashita et al., 2007; Saito et al., 2012); therefore radioactive materials may have had indirect positive effects on animal abundances by removing human pressures (Baker and Chesser, 2000; IAEA, 2006). If the wild boar and sika deer populations increase, crop damage (Saito et al., 2011) in areas surrounding the evacuation zone and grazing damage in natural ecosystems (Takatsuki, 2009) could become a concern in Fukushima.

These factors could obscure the negative effects of radiation, making it difficult to detect the detrimental effects on large animal abundances, except for species with low dispersal and radiation sensitivity.

The chronic effects on animal abundance following the Chernobyl accident are controversial (Beresford and Copplestone, 2011; Garnier-Laplace et al., 2011). In forest sites around the Chernobyl NPP, mammal, bird, and invertebrate abundances decreased with increasing radiation (Møller and Mousseau, 2007; 2009; 2011). However, the chronic effects on abundance are obscure, except for individual level damages (Beresford and Copplestone, 2011). Diversity and abundance of small mammals 
was not reduced in most radioactive sites around the Chernobyl NPP (Baker et al., 1996).

A monitoring system to verify various outcomes should be constructed immediately for the Fukushima accident, and early period radiation monitoring is especially crucial to clarify the biological effects of the released radioactive material (Geras'kin et al., 2008).

This study is based on the assumption that dose rate, to which wildlife is exposed, is equivalent to the external air dose rate. Hence, the contribution of the internal dose rate due to the incorporation of radionuclides by biota is ignored; the huge variability of absorbed dose rates between species for the same medium concentration is also not taken into account. Moreover, depending on the exposure scenario, the internal contamination may constitute the major contributor to the total dose rate (e.g. Beresford et al., 2008). Therefore, the results reported by the present study may have a possibility to underestimate the absorbed dose rate and the risk for small mammals. In reality, internal exposure is considered to play an important role in irradiation of non-human biota, especially in the remote period. Hence for assuring more robustness in the prediction, authors recommend assessing the transfer factors soil/biota for example by using ERICA tool (Brown et al., 2008, Garnier-Laplace et al. 2011, Wood et al., 2008) for further study. Also, we are aware that the proper unit to express dose rate for non-human species is the Gy per unit time and the Sv is a risk metric dedicated to human radioprotection. As we relied on the information of postaccident early stage in 2011, majority of information was expressed in Sv. Hence, the units of the TDR5 values were converted into $\mu \mathrm{Sv} / \mathrm{h}$. For future studies, we recommend to use Gy for evaluating radiation pollution risk for non-human species.

\section{ACKNOWLEDGEMENTS}

The data regarding air radiation dose rates was collected and made available on the web by local governments, MEXT, TEPCO, and Fukushima University. This study was supported in part by the JSPS Global COE Program "Global eco-risk management from Asian viewpoints" and a Grant-in-Aid for JSPS Fellows (2011, KAKENHI No.23-4520).

\section{REFERENCES}

Baker, R.J., Chesser, R.K., 2000: The chornobyl nuclear disaster and subsequent creation of a wildlife preserve. Environmental Toxicology and Chemistry 19, 1231-1232.

Baker, R.J., Hamilton, M.J., van Den Bussche, R.A., Wiggins, L.E., Sugg, D.W., Smith, M.H., Lomakin, M.D., Gaschak, S.P., Bundova, E.G., Rudenskaya, G.A., Chesser, R.K., 1996: Small mammals from the most radioactive sites near the Chornobyl Nuclear Power Plant. Journal of Mammalogy 77, 155-170.

Beresford, N.A., Balonov, M., Beaugelin-Seiller, K., Brown, J., Copplestone, D., Hingston, J.L., Horyna, J., Hosseini, A., Howard, B.J., Kamboj, S., Nedveckaite, T., Olyslaegers, G., Sazykina, T., Vives i Batlle, J., Yankovich, T.L., Yu. C., 2008: An international comparison of models and approaches for the estimation of the radiological exposure of non-human biota. Applied Radiation and Isotopes, 66, 1745-1749.
Beresford, N.A., Copplestone, D., 2011: Effects of ionizing radiation on wildlife: What knowledge have we gained between the Chernobyl and Fukushima accidents? Integrated Environmental Assessment and Management 7, 371-373.

Brown, J. E., Alfonso, B., Avila, R., Beresford, N., Copplestone, D., Pröhl, G., Ulanovski, A., 2008: The ERICA Tool. Journal of Environmental Radioactivity, 99, 1371.

Burrough, P.A., McDonnell, R., 1998: Principles of geographical information systems (spatial information systems). Oxford University Press, New York.

Garnier-Laplace, J., Beaugelin-Seiller, K., Hinton, T.G., 2011: Fukushima wildlife dose reconstruction signals ecological consequences. Environmental Science \& Technology 45, 50775078 .

Geras'kin, S.A., Fesenko, S.V., Alexakhin, R.M., 2008: Effects of non-human species irradiation after the Chernobyl NPP accident. Environmental International 34, 880-897.

IAEA, 2006: Environmental consequences of the chernobyl accident and their remediation: twenty years of experience. Report of the chernobyl forum expert group 'environment'. International Atomic Energy Agency, Vienna.

Møller, A.P., Mousseau, T.A., 2007: Species richness and abundance of forest birds in relation to radiation at Chernobyl. Biology Letters 3, 483-486.

Møller, A.P., Mousseau, T.A., 2009: Reduced abundance of insects and spiders linked to radiation at Chernobyl 20 years after the accident. Biology Letters 23, 356-359.

Møller, A.P., Mousseau, T.A., 2011: Efficiency of bio-indicators for low-level radiation under field conditions. Ecological Indicators 11, 424-430.

MEXT, 2011: Distribution map of radiation dose around Fukushima Dai-ichi \& Dai-Ni NPP (as of July 11, 2011). Ministry of Education, Culture, Sports, Science and Technology. Retrieved 28 December 2011 from http://www.mext.go.jp/component/english/__icsFiles/afieldfile/2 011/08/05/1305904_0720.pdf

Miyashita, T., Suzuki, M., Takada, M., Fujita, G., Ochiai, K., Asada, M., 2007: Landscape structure affects food quality of sika deer (Cervus nippon) evidenced by fecal nitrogen levels. Population Ecology 49, 185-190.

NISA, 2011: Regarding response to the specific spots estimated to exceed an integral dose of 20mSv over a one year period after the occurrence of the accident ("specific spots recommended for evacuation"). Nuclear and Industrial Safety Agency. Retrieved 28 December 2011 from http://www.nisa.meti.go.jp/english/press/2011/06/en20110621 2.pdf

Ohdachi, S.D., Ishibashi, Y., Iwasa, M.A., Saitoh, T., 2009: The wild mammals of Japan. Shoukadoh Book Sellers, Kyoto.

Olival, K.J., Higuchi, H., 2006: Monitoring the long-distance movement of wildlife in Asia using satellite telemetry. In 
McNeely, J.A., McCarthy, T.M., Smith, A., Olsvig-Whittaker, L., Wikramanayake, E.D., (eds.) Conservation biology in Asia. The Society for Conservation Biology Asia Section and Resources Himalaya, Kathmandu, 319-339.

R Development Core Team, 2010: R: A Language and Environment for Statistical Computing, Vienna.

Radiation measurement team of Fukushima University, 2011: Changes of Fukushima City's air radiation dose (7 May 2011). Retrieved 28 December 2011 from http://www.sss.fukushimau.ac.jp/FURAD/FURAD/doc-fukushimacity.html (in Japanese)

Saito, M., Koike, F., Momose, H., Mihira, T., Uematsu, S., Ohtani, T., Sekiyama, K., 2012: Forecasting the range expansion of a recolonising wild boar Sus scrofa population. Wildlife Biology 18, 383-392.

Saito, M., Momose, H., Mihira, T., 2011: Both environmental factors and countermeasures affect wild boar damage to rice paddies in Boso Peninsula, Japan. Crop Protection 30, 10481054.

Sazykina, T., Kryshev, A., Sanina, K., 2009: Non-parametric estimation of thresholds for radiation effects in vertebrate species under chronic low-LET exposures. Radiation and Environmental Biophysics 48, 391-404.

Science Council of Japan, 2011: Report to the Foreign Academies from Science Council of Japan on the Fukushima Daiichi Nuclear Power Plant Accident. Retrieved 28 December 2011 from http://www.scj.go.jp/en/report/houkoku-1105027.pdf

Takatsuki, S., 2009: Effects of sika deer on vegetation in Japan: A review. Biological Conservation 142, 1922-1929.

UNSCEAR, 2000: Sources and Effects of Ionizing Radiation. Report to General Assembly, with Scientific Annexes, United Nations, New York.

Watson, D.F., Philip, G.M., 1985: A refinement of inverse distance weighted interpolation. Geoprocessing 2, 315-327.

Wood, M.D., Marshall, W.A., Beresford, N.A., Jones, S.R., Howard, B.J., Copplestone, D., Leah, R.T., 2008: Application of the ERICA Integrated Approach to the Drigg coastal sand dunes. Journal of Environmental Radioactivity, 99, 1484-1495. 